\title{
Surgical Results of 300 Patients of Lumbar Spine Diseases with Special Concern to "Pseudoradicular Pain"
}

\author{
Jun-ichiro Ishikawa, Akinori Kondo, Tsuneki Konishi, \\ Kenji Kanemaru and Masanori Morimoto \\ Department of Neurosurgery, Fukui Red Cross Hospital, Fukui
}

\begin{abstract}
The results of the microsurgical treatment of 300 patients with painful lumbar spinal diseases were reported. Radical removal of the disc material, preservation of the epidural fat tissue around the lumbar nerve roots, and meticulous hemostasis produced good results. Yet, even with this technique, a pseudoradicular or referred pain still developed after surgery, despite of the disappearance of a radicular pain or radicular signs.

Pseudoradicular pain is characterized by: 1) Lasègue sign only after raising the straightened leg more than 40 degrees; 2) no radicular signs; 3 ) marked pains localized in the area innervated by the dorsal ramus which is involved in a pathological process; and 4) no pain in the popliteal fossa. ${ }^{10}$ )

Our operative results revealed that this uncomfortable pain developed most frequently after operative procedures involving facets and lateral recesses, such as in facetectomy or foraminotomy for superior facet syndrome ( $80 \%$ postoperatively) and for cases of lumbar herniated disc $(63 \%$ postoperatively). The pain could be elicited by stimulation or irritation of the dorsal rami of the lumbar spinal nerves during surgery involving the articular facets. That was why pseudoradicular pain frequently developed after treatment of superior facet syndrome based on hypertrophied articular process or lumbar herniated discs.
\end{abstract}

Key words: pseudoradicular pain, lumbar herniated dise, superior facet syndrome

\section{Introduction}

The application of microsurgical techniques to lumbar spine surgery has numerous advantages. It may permit early mobilization of the patients and may shorten hospitalization by lessening damage to the normal tissue by preserving the epidural fat around the nerve roots, and by allowing radical removal of the disc material. Meticulous hemostasis also serves to shorten the hospital stay. Although radical removal of the disc material and spondylotic spurs under the microscope appears to reduce the reccurrence rate of radicular pain, some patients complain of a "pseudoradicular pain", or referred pain, postoperatively. Pseudoradicular pain is characterized by: 1) positive Lasègue sign only after the straight leg is raised more than 40 degrees; 2) no radicular signs; 3) marked pains localized in the area innervated by the dorsal ramus which is involved in a pathological process; and 4) pain which spares the popliteal fossa. ${ }^{10}$ ) Since injection of hypertonic saline into the intervertebral joints causes a referred pain in the gluteal region and at the posterior aspect of the thigh, ${ }^{7,8}$ referred pain is not thought to be of discal origin. In fact, referred pain is often expressed as a spontaneous pain and/or a tenderness in the lateral upper one third of the gluteal region, which are often present in patients with painful lumbar spine diseases, either before or after surgery, or both.

In this communication, the postoperative occurrence of pseudoradicular pain was evaluated in 300 patients with lumbar pathology, and consideration was given to its pathogenesis and treatment.

\section{Materials and Methods}

Three-hundred cases of painful lumbar spine diseases

Received July 9, 1981; $\quad$ Accepted February 23, 1982

Author's present address: T. Konishi, M. D., Department of Neurosurgery, Kyoto University Kyoto, Japan; K. Kanemaru, M. D., Department of Neurosurgery, Mie University Tsu, Mie, Japan; M. Morimoto, M. D., Department of Neurosurgery, Kochi Medical College Kochi, Japan. 
were surgically treated at the Department of Neurosurgery, Fukui Red Cross Hospital, from April 1975 to December 1979. The operative results were analyzed in these 300 patients (147 men and 153 women).

Tenderness in the lateral upper one third of the gluteal region, which is one of the most common signs of pseudoradicular pain, was examined during the hospital stay of these patients.

The diagnosis of painful lumbar spine diseases was made by neurological examination, and their etiology was confirmed by lumbar myelography with Dirax ${ }^{\circledR}$. Lumbar herniated discs were found in 190 cases (Group I) ; lumbar spinal canal stenosis combined with herniated discs in 49 cases (Group II); lumbar canal stenosis in 46 cases (Group III); and superior facet syndromes in 15 cases (Group IV).

The operations were performed under a microscope with the following technique. For a herniated disc, a small portion of the upper lamina and the medial portion of the facet on the affected side were partially removed with a high speed air drill and an oblique punch rongeur. To avoid reccurrence, these procedures were performed bilaterally in the most recent cases. For canal stenosis with herniated discs, a conventional laminectomy was performed after removal of the herniated discs, and for canal stenosis with or without spondylosis, a conventional laminectomy alone was performed. For superior facet syndrome produced by compression of the lumbar nerve roots with an anomalously enlarged superior articular process, a partial facetectomy and foraminotomy without discectomy were performed.

\section{Operative Results}

The average period of bed rest was 4 days for Group I, 10 days for Groups II and III, and 2 days for Group IV, and the average hospital stay of the patient was 15 days for Group I, 25 days for Groups II and III, and 10 days for Group IV (Table 1).

Table 1 Average period of bed rest and hospital stay of operated patients

\begin{tabular}{lcc}
\hline & $\begin{array}{c}\text { Average period } \\
\text { of bed rest }\end{array}$ & $\begin{array}{c}\text { Average period } \\
\text { of hospital stay }\end{array}$ \\
Group I & $3.8 \pm 1.9$ days & $15.5 \pm 5.1$ days \\
Groups II \& III & $9.7 \pm 1.9$ & $25.4 \pm 6.1$ \\
Group IV & $1.8 \pm 0.4$ & $10.2 \pm 1.2$ \\
\hline
\end{tabular}

Group I : Cases of herniated discs only

Group II : Cases of canal stenosis combined with herniated discs

Group III: Cases of canal stenosis only

Group IV: Cases of superior facet syndrome
The tenderness in the gluteal region, used as an index of the pseudoradicular pain, was classified as follows: The patients were divided into 4 groups. Type I consisted of 89 cases without pseudoradicular pains either before or after surgery. Type II included 25 cases who had tenderness in the gluteal region before surgery which disappeared postoperatively. Eighty-two cases in Type III had pseudoradicular pains both before and after surgery. Type IV included 104 cases who had no pseudoradicular pains before surgery, but developed tenderness in the gluteal region postoperatively (Table 2).

Table 2 The tenderness in the gluteal region before and after surgery

\begin{tabular}{lccc} 
& preoperative & postoperative & cases \\
Type I & - & - & 89 \\
Type II & + & - & 25 \\
Type III & + & + & 82 \\
Type IV & - & + & 104 \\
\hline
\end{tabular}

Table 3 The incidence of tenderness in the gluteal region for each operative procedure

\begin{tabular}{|c|c|c|c|c|c|}
\hline & $\begin{array}{l}\text { Type I } \\
\text { (cases) }\end{array}$ & $\begin{array}{c}\text { Type II } \\
\text { (cases) }\end{array}$ & $\begin{array}{c}\text { Type III } \\
\text { (cases) }\end{array}$ & $\begin{array}{c}\text { Type IV } \\
\text { (cases) }\end{array}$ & $\begin{array}{c}\text { Total } \\
\text { (cases) }\end{array}$ \\
\hline Group I & 53 & 18 & 54 & 65 & 190 \\
\hline Group II & 12 & 3 & 12 & 22 & 49 \\
\hline Group III & 21 & 4 & 8 & 13 & 46 \\
\hline Group IV & 3 & 0 & 8 & 4 & 15 \\
\hline
\end{tabular}

Table 4 The incidence of tenderness in the gluteal region before and after surgery

\begin{tabular}{lcccc}
\hline & \multicolumn{2}{c}{ Types II + III } & \multicolumn{2}{c}{ Types III + IV } \\
(cases) & $(\%)$ & (cases) & $(\%)$ \\
Group I & 72 & $(38)$ & 119 & $(63)$ \\
Group II & 15 & $(31)$ & 34 & $(69)$ \\
Group III & 12 & $(54)$ & 21 & $(46)$ \\
Group IV & 8 & $(53)$ & 12 & $(80)$ \\
\hline
\end{tabular}

Types II + III: preoperative incidence

Types III + IV: postoperative incidence

Table 5 The levels of the surgical intervention for herniated discs

\begin{tabular}{crr}
\hline & \multicolumn{1}{c}{ Levels } & Cases \\
\cline { 3 - 3 } 1 level & $\mathrm{L} 3 / 4$ & 2 \\
& $\mathrm{~L} 4 / 5$ & 111 \\
& $\mathrm{~L} 5 / \mathrm{S} 1$ & 20 \\
\hline \multirow{2}{*}{ 2 levels } & $\mathrm{L} 3 / 4, \mathrm{~L} 4 / 5$ & 17 \\
& $\mathrm{~L} 4 / 5, \mathrm{~L} 5 / \mathrm{S} 1$ & 37 \\
\hline 3 levels & $\mathrm{L} 3 / 4, \mathrm{~L} 4 / 5, \mathrm{~L} 5 / \mathrm{S} 1$ & 3 \\
\hline
\end{tabular}


Table 6 The incidence of tenderness in the gluteal region after partial laminectomy

\begin{tabular}{lll}
\hline L4/5 & intervertebral & $73 / 111$ cases \\
& discs & $(66 \%)$ \\
L5/S1 & intervertebral & $8 / 20$ cases \\
& discs & $(40 \%)$ \\
\hline
\end{tabular}

Tenderness in the gluteal region was noted more frequently after operative procedures ( 186 cases) than before surgery (107 cases), and the occurrence rates of pseudoradicular pain in each group are shown in Table 3 and Table 4.

Among the 190 patients in Group I, surgical intervention was at the L4/5 intervertebral space in 111 patients and at the L5/S1 in 20 patients (Table 5). The relationship between the levels of the partial laminectomy and the occurrence of pseudoradicular pain is shown in Table 6.

Tenderness in the gluteal region was more frequently elicited after partial laminectomy at the $\mathrm{L} 4 / 5$ level than at the L5/S1, although the numbers of operated discs at the L5/S1 were limited. In almost all cases, pseudoradicular pain was easily controlled by local anesthetics in the gluteal region and at other points of tenderness where the pain radiated, while in a few cases the effect of local anesthesia was only transient.

\section{Disccussion}

In 1911, Goldthwait ${ }^{5)}$ first reported abnormalities of the lumbosacral articulation which caused sciatica. Kellgren ${ }^{7,8)}$ experimentally elicited referred pains by injection of hypertonic saline into various muscles and interspinous ligaments and mapped the segmental areas of deep pains and tenderness. The same technique was used by other authors to produce the same kinds of pain from muscles and other supportive structures. $^{3,6,19,20)}$ In 1956, Pedersen et al. ${ }^{15)}$ reported that the posterior rami of the lumbar spinal nerve projects sensory fibers to the fascia, ligaments, periosteum, and the intervertebral joints, and that the sinu-vertebral nerves supply the posterior longitudinal ligament, dura mater, periosteum, and blood vessels (Fig. 1). They also suggested that a painful stimulus to any deep structure could provoke low back and leg pain. Little attention was paid to these studies, however, until 1971 when Rees ${ }^{16)}$ reported a new approach of transcutaneous section of the posterior rami as a successful treatment for intervertebral disc syndrome. After this report, some physicians recognized the importance of the posterior ramus in pseudoradicular pain. ${ }^{4,9,12,17)}$ Bogduk $^{1)}$ described four anatomical elements (i.e., lumbar nerve roots, lumbar spinal nerves, dorsal rami, and sinu-vertebral nerves) that are responsible for low

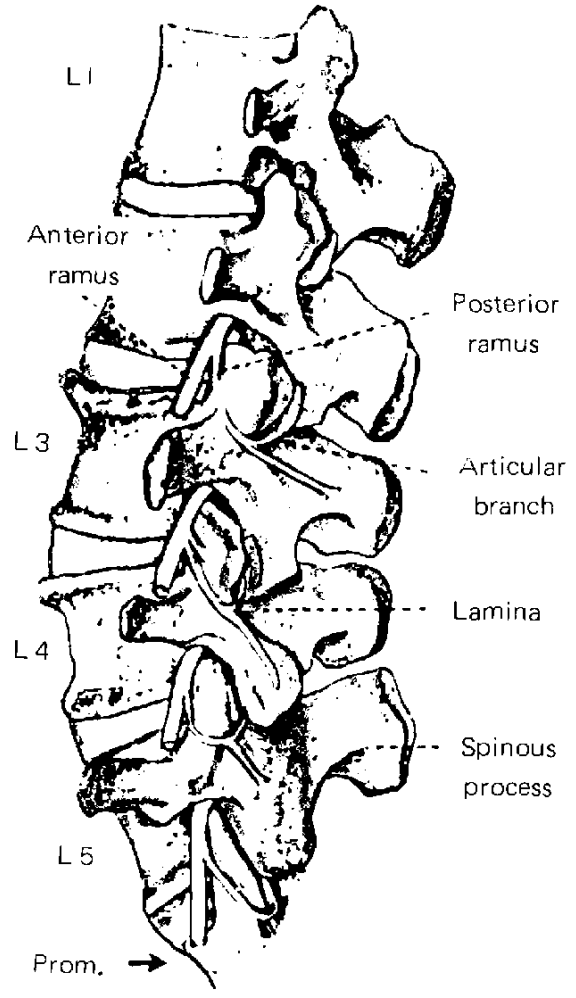

Fig. 1 Diagram of the course of the posterior ramus of the lumbar spinal nerve and its branches. Redrawn from Pedersen et al. ${ }^{15)}$ (Fig. 2, $379 \mathrm{pp}$ ) with permission from the J Bone Joint Surg, Inc.

back pain and lower limb symptoms, and pointed out that two mechanisms might produce these symptoms: "Type 1 mechanism" was the direct irritation of nerve roots or spinal nerves and "Type 2 mechanism" was stimulation of the dorsal rami or sinu-vertebral nerves.

In our series, even after successful operative relief of radicular pains and the disappearance of other radicular signs, $62 \%$ of the patients ( 186 out of 300 patients) still complained of some amount of pain in the lateral upper one third of the gluteal region or at the posterior aspect of the thigh when they started to walk after surgery. These pains usually diminished with several injections of local anesthetics to the tender points. Therefore, such pains were considered as pseudoradicular or referred pains, rather than as radicular pains.

Pseudoradicular pain occurrence most frequently in Group IV and least in Group III. This was because with conventional laminectomy (Group III), the articular facets are not disrupted by surgery, while for superior facet syndrome (Group IV), the medial portion of the facets were partially removed and consequently the facets were most highly disrupted during this surgery. For herniated discs (Group I), a partial 


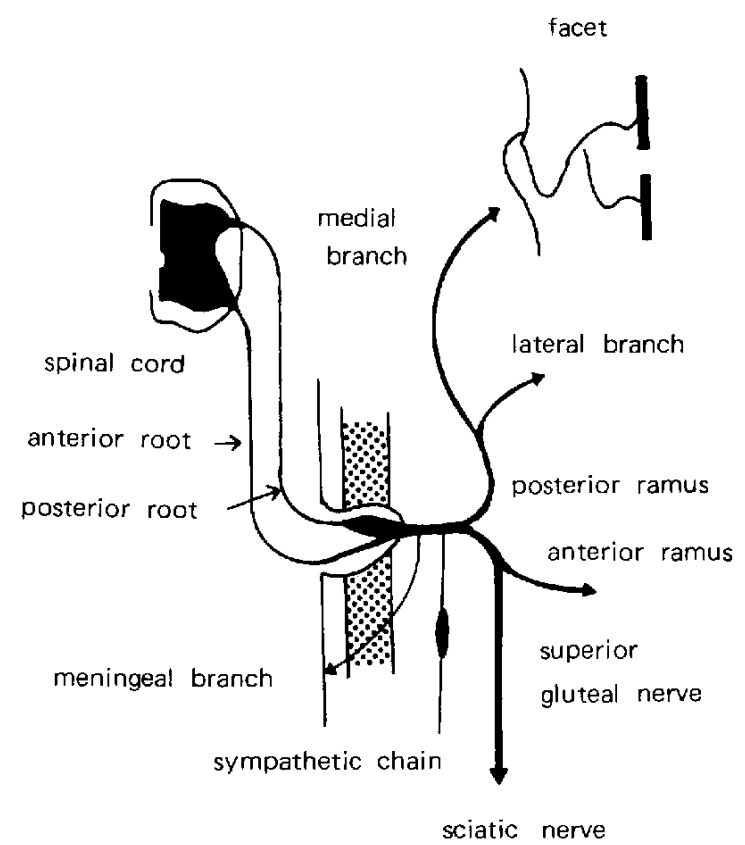

Fig. 2 Schematic drawing of nerve roots and sciatic nerve explaining mechanism of "pseudoradicular pain" in the lower lumbar region.

facetectomy and/or foraminotomy were performed and the articular capsules of the facets could have been moderately traumatized by this procedure. Our results showed that pseudoradicular pain was produced by a surgical intervention at either the $\mathrm{L} 4 / 5$ or $\mathrm{L} 5 / \mathrm{S} 1$ intervertebral joints, especially at the former level. This difference after operation may be due in part to the different innervation of the facets by the posterior ramus, or partially to the difference in the areas where the pain would radiate. At levels L1 through L4, each dorsal ramus runs across the root of the superior articular process, whereas the L5 dorsal ramus runs along a groove between the ala of the sacrum and its superior articular process. ${ }^{2)}$ In consequence, the dorsal ramus at the L4/5 level is likely to be injured upon partial removal of the medial portion of the superior articular process during facetectomy.

Pseudoradicular pain was considered to be caused by dorsal rami injured during operative procedures such as facetectomy or foraminotomy. Irritation of the medial branch of the dorsal ramus was referred to the anterior ramus, including the superior gluteal or sciatic nerve (Fig. 2), and finally evoked pseudoradicular pain.

Recently we have been performing a radiofrequency neurotomy of the posterior ramus for the relief of pseudoradicular pain. ${ }^{11,13,14,18)}$ The results will be reported in a separate paper.

\section{Conclusions}

Even after successful operation for painful lumbar diseases, $62 \%$ of the patients still complained of tenderness in the gluteal region or at the posterior aspect of the thigh despite disappearance of the radicular pain or radicular signs. Such a pseudoradicular pain was produced by the disruption of the facet and the resulting irritation of the posterior ramus of the lumbar spinal nerves. The pain most frequently appeared after operation of superior facet syndrome (hypertrophied superior articular process) and after disc surgery at the $\mathbf{L} 4 / 5$ level.

\section{Acknowledgments}

The authors would like to thank Dr. Junichiro Kawamura, Tenri Hospital, for his kind and valuable advice.

\section{References}

1) Bogduk N: The anatomy of the lumbar intervertebral disc syndrome. Med $J$ Aust 1: 878 881, 1976

2) Bogduk N, Long DM: The anatomy of the so-called "articular nerves" and their relationship to facet denervation in the treatment of low-back pain. $J$ Neurosurg 51: 172-177, 1979

3) Feinstein B, Langton JNK, Jameson RM, Schiller F: Experiments on pain referred from deep somatic tissues. J Bone Joint Surg [Am] 36-A: 981-997, 1954

4) Fox JL, Rizzoli HV: Identification of radiologic coordinates for the posterior articular nerve of Luschka in the lumbar spine. Surg Neurol 1: 343-346, 1973

5) Goldthwait JE: The lumbar-sacral articulation. An explanation of many cases of "lumbago", "sciatica" and paraplegia. Boston Medical and Surgical Journal 64: 365-372, 1911

6) Inman VT, Saunders JBdeCM: Referred pain from skeletal structures. $J$ Nerv Ment Dis 99 : 660-667, 1944

7) Kellgren JH: Observations on referred pain arising from muscle. Clin Sci 3: 175-190, 1938

8) Kellgren $\mathrm{JH}$ : On the distribution of pain arising from deep somatic structures with charts of segmental pain areas. Clin Sci 4: 35-46, 1939

9) King JS, Lagger R: Sciatica viewed as a referred pain syndrome. Surg Neurol 5: 46-50, 1976

10) Loew F, Caspar W: Surgical approach to lumbar disc herniations, in Krayenbuhl $\mathrm{H}(e d)$ : Advances and Technical Standards in Neurosurgery, vol. 5. Wien, Springer-Verlag, 1978, pp 153-174

11) Lora J, Long D: So-called facet denervation in the management of intractable back pain. Spine 1: 121126,1976

12) Macnab I, Cuthbert FH, Godfrey CM: The incidence 
of denervation of the sacrospinales muscles following spinal surgery. Spine 2: 294-298, 1977

13) Oudenhoven RC: Articular rhizotomy. Surg Neurol 2: 275-278, 1974

14) Oudenhoven RC: Paraspinal electromyography following facet rhizotomy. Spine 2: 299-304, 1977

15) Pedersen HE, Blunck CFJ, Gardner E: The anatomy of lumbosacral posterior rami and meningeal branches of spinal nerves (sinu-vertebral nerves). $J$ Bone Joint Surg $[\mathrm{Am}]$ 38: 377-391, 1956

16) Rees WES: Multiple bilateral subcutaneous rhizolysis of segmental nerves in the treatment of the intervertebral disc syndrome. Ann Gen Prac 26: 126-127, 1971

17) Shealy $\mathrm{CN}$ : The role of the spinal facets in back and sciatic pain. Headache 14: 101-104, 1974
18) Shealy $\mathrm{CN}$ : Percutaneous radiofrequency denervation of facets. $J$ Neurosurg $43: 448-451,1975$

19) Sinclair DC, Feindel WH, Weddel G, Falconer MA: The intervertebral ligaments as a source of segmental pain. $J$ Bone Joint Surg [Br] 30: 515-521, 1948

20) Steinbrocker $O$, Isenberg $S A$, Silver $M$, Neustadt $D$, Kuhn P, Schittone M : Observations on pain produced by injection of hypertonic saline into muscles and other supportive tissues. $J$ Clin Invest 32: 1045-1051, 1953

Request reprints to: J. Ishikawa, M.D., Department of Neurosurgery, Fukui Red Cross Hospital, 2-4-1 Tsukumi, Fukui 910, Japan. 